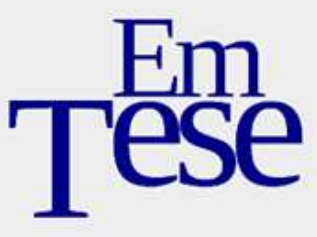

\title{
Contra o consenso: o "político" em Chantal Mouffe e os desafios na construção de uma nova hegemonia democrática radical
}

\author{
João Gabriel Vieira Bordin ${ }^{1}$
}

\section{Introdução}

O presente artigo se debruça sobre alguns dos problemas teóricos e empíricos levantados por Mouffe na constituição do que ela chama de nova hegemonia democrática radical e plural, uma preocupação que é o grande leitmotiv que atravessa sua obra como um todo, desde a publicação em 1985, com Ernesto Laclau, de Hegemony and Socialist Strategy. A resposta que ela dá passa, como veremos, pela reafirmação da dimensão "do político", isto é, do antagonismo contra o paradigma liberal-democrata hegemônico que supõe a possibilidade (e a desejabilidade) do consenso, e que ela denomina genericamente de "modelo de consenso". Além da conclusão e de uma breve introdução acerca das implicações teóricas das teses de Laclau e Mouffe para a tradição marxista da qual ambos se afastam, o artigo subdividese em outras duas seções. A primeira analisa o significado do político em Mouffe e suas relações com o pluralismo agonista advogado por ela, explicitando seus pontos de tensão com o modelo de consenso. Este é o momento dos problemas teóricos. Num segundo momento, a seção seguinte discute algumas implicações desses problemas em relação aos desafios empíricos que enfrenta a prática política contemporânea a fim de avançar em direção a uma democracia radical e plural. O artigo conclui chamando atenção para o que julgamos ser o desafio fundamental do modelo pluralista agonista:

\footnotetext{
${ }^{1}$ Mestrando do curso de Sociologia Política da Universidade Federal de Santa Catarina (UFSC). Contato: joao.g.bordin@hotmail.com
}

Em Tese, Florianópolis, v. 12, n. 1, jan./jul., 2015. ISSN: 1806-5023 


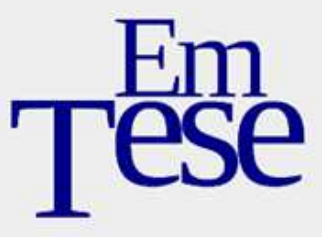

lograr unir, numa cadeia de equivalências democráticas, uma esquerda tradicionalmente fragmentada por vários sujeitos sociais potencialmente antagonistas.

\section{Mouffe e a tradição marxista: breves apontamentos}

Não há nem nunca houve um marxismo único e distinto, concebido como um sistema teórico fechado e acabado, legado por Marx e posteriormente desenvolvido de forma linear por intelectuais e políticos revolucionários passando o bastão uns aos outros até os dias de hoje. A ênfase que se dá a determinados aspectos do pensamento de Marx, a própria maneira de interpretá-lo ou de compreender o sinuoso caminho trilhado por ele posteriormente depende, de saída, de qual marxismo estamos falando. Neste sentido, o marxismo é uma espécie de significante vazio, ou seja, não tem um sentido imanente, fora das relações que o construíram e o constroem. Embora múltiplo e diverso, o marxismo é o resultado de infinitas disputas pela hegemonia dessa tradição política e intelectual a fim de conferir-lhe um sentido. E uma vez que a disputa pela hegemonia é sempre um jogo de deslocamento entre fronteiras de significados com o fito de um só tempo incluir e excluir determinados elementos, dependendo da perspectiva que olhemos alguns representantes da tradição marxista serão "menos" ou "mais" marxistas, ou sequer serão "marxistas" enquanto outros serão "verdadeiros" marxistas.

Essa interpretação discursiva da história do marxismo permite que situemos, a um só tempo, Ernesto Laclau e Chantal Mouffe, entre outros pós-marxistas, dentro do campo desta tradição teórica tanto quanto fora. Como eles próprios afirmam, são tanto pós-marxistas quanto pós-marxistas - isto é, ao mesmo tempo em que se apropriam criticamente de alguns elementos dessa tradição teórica, procuram ir além dela incorporando outras contribuições advindas de novas correntes de pensamento, como o pós-modernismo. Essa pretensão, naturalmente, não poderia deixar de ser questionada 


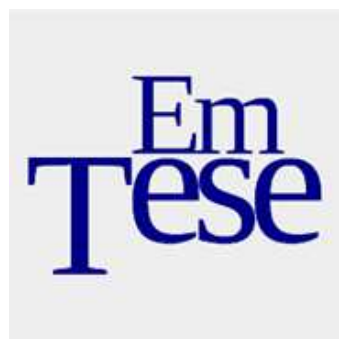

por outros representantes desta tradição intelectual, digamos, mais puristas. Afinal, os autores de Hegemonia e Estratégia Socialista refutam premissas centrais ao pensamento marxista - notadamente a centralidade de classe, a estratégia revolucionária e a utopia socialista entendida como sociedade homogênea e transparente. Diferentemente do marxismo ortodoxo, no entanto, para Laclau e Mouffe não se trata de (re)encontrar o "verdadeiro" marxismo, cujo essencialismo é, na verdade, uma impostura ontológica. Eles se colocam, explicitamente, numa perspectiva que busca não apenas ir além do marxismo, mas também relê-lo à luz dos problemas atuais; tanto extrair de Marx e dos diversos marxismos elementos tomados à revelia, na medida em que se fizerem úteis à luz de tais problemas, quanto enxertar neles elementos teóricos de outras tradições intelectuais, sem preocupar-se, ao fazê-lo, em observar dogmas e preconceitos.

\begin{abstract}
Reler a teoria marxista à luz dos problemas contemporâneos necessariamente envolve desconstruir as categorias centrais dessa teoria. Isto é o que tem sido denominado nosso "pós-marxismo". Nós não inventamos este rótulo [...]. Mas [...] nós não lhe opomos desde que ele seja corretamente entendido: como o processo de reapropriação de uma tradição intelectual, assim como o processo de ir além dela. E ao empreender essa tarefa, é importante frisar que ela não pode ser concebida apenas como uma história interna do marxismo. Muitos antagonismos sociais, muitas questões que são cruciais para o entendimento das sociedades contemporâneas pertencem a campos de discursividade que são externos ao marxismo, e não podem ser reconceitualizados em termos de categorias marxistas [...] (LACLAU E MOUFFE, 2001, p.ix).
\end{abstract}

Precisamente isto é o que fazem os dois autores em Hegemony and Socialist Strategy (HSS), uma obra publicada em 1985 e que se tornou paradigmática no campo da teoria (e da) política pós-marxista. Ao mesmo tempo em que se enfrentam com a tradição marxista ortodoxa ao rever a trajetória do conceito de hegemonia, apontando seus limites e ambiguidades, reelaboram-no a partir de seu último e mais profícuo desenvolvimento em Gramsci², incorporando outros paradigmas teóricos estranhos ao

\footnotetext{
${ }^{2}$ Citar Gramsi, assim de passagem, não faz jus à importância que ele tem na teoria de Laclau e Mouffe. Gramsci já havia compreendido a crescente complexificação das sociedades capitalistas avançadas e as implicações negativas disso para a teoria marxista. "Nesse contexto, o conceito de hegemonia surge para preencher o vazio deixado pela categoria marxista de necessidade histórica e responder às situações
}

Em Tese, Florianópolis, v. 12, n. 1, jan./jul., 2015. ISSN: 1806-5023 


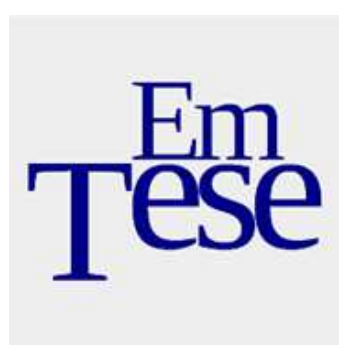

marxismo, especialmente a psicologia de Lacan, o desconstrutivismo de Derrida e a filosofia da linguagem de Wittgenstein. Com isso, Laclau e Mouffe procuraram desenvolver uma nova estratégia democrática radical capaz de enfrentar os problemas sociais contemporâneos e de apontar uma saída para o que os autores entendem como uma crise vivida pela esquerda desde os anos 1970, incapaz de fazê-lo ela mesma porque ainda presa no interior do quadro objetivista, essencialista e determinista do marxismo ortodoxo.

É lícito perguntar se toda a leitura que fazem Laclau e Mouffe do marxismo é justa. Precisamente uma das fraquezas em sua argumentação é que, na tentativa de desconstruir o marxismo, eles parecem construir um adversário contra o qual lutar. ${ }^{3}$ Por certo, deixam de fora muitas contribuições ao marxismo que não caem vulgarmente no determinismo e reducionismo do marxismo ortodoxo e, ipso facto, não poderiam ser identificadas estritamente com ele, mas que, nem por isso, chegam às mesmas conclusões de Laclau e Mouffe. Até que ponto foram eles bem sucedidos na sua tarefa não nos cabe perguntar aqui. O nos interessa é compreender que o ponto central da sua crítica atinge toda concepção que se afirma marxista simplesmente porque ela está endereçada a uma categoria que jaz no coração desta tradição teórica: a centralidade do conceito de classe. Apoiando-se nos avanços filosóficos da pós-modernidade - que, seja dito de passagem, não descreve um sistema teórico coerente, mas o movimento de

concretas de contingência." (ALVES, 2010, p.83-4). Embora ainda não houvesse superado a ideia de centralidade de classe na formação das identidades, ao deslocar a sociedade civil para fora da estrutura e para dentro da superestrutura Gramsci reafirmou a preeminência do político sobre o econômico e o papel da cultura (ideologia) na constituição e reprodução das relações de dominação, isto é, da hegemonia (BOBBIO, 1982). Em termos da dialética entre universal e particular, central para o argumento defendido em HSS, assim coloca a questão Laclau (2004, p.56): "Para Gramsci, [...] a única universalidade que a sociedade pode alcançar é uma universalidade hegemônica - uma universalidade contaminada pela particularidade. [...] a emancipação universal se alcança somente através de uma identificação transitória com os objetivos de um setor determinado, o que significa que é uma universalidade contingente que requer constitutivamente mediação política e relações de representação".

${ }^{3}$ Como afirmam Tormey e Townshend (2006, p.107), "eles [Laclau e Mouffe] criticaram efetivamente um certo tipo de marxismo, mas nós ainda podemos nos perguntar se a sua crítica do marxismo em geral era tão incisiva quanto eles esperavam. [...] Assim, o marxismo totalitário soviético era diferente do marxismo democrático do Ocidente, que, de Marx e Engels a Kautsky e os eurocomunistas, via o parlamento como central na transição socialista, tendo pouco a ver com o fundamental "imaginário jacobinista’ da Revolução Russa.”

Em Tese, Florianópolis, v. 12, n. 1, jan./jul., 2015. ISSN: 1806-5023 


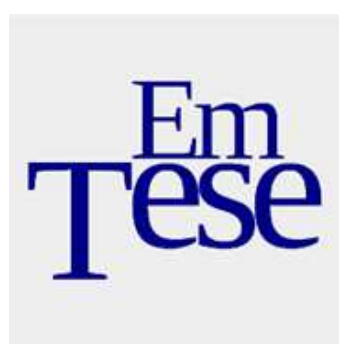

desconstrução da grande narrativa universalista e racionalista da modernidade empreendida de várias perspectivas teóricas diferentes (MOUFFE, 1999, p.107-108) -, Laclau e Mouffe vão rejeitar o essencialismo e determinismo que deriva da centralidade de classe na tradição marxista. No lugar da classe, o antagonismo "torna-se o novo conceito central" (THERBORN, 2008, p.141).

O essencialismo e determinismo a que se referem Laclau e Mouffe remetem-se à centralidade do conceito de classe (que, no caso do proletariado, conferir-lhe-ia uma perspectiva privilegiadamente universal) na construção das identidades coletivas, centralidade que estaria dada não por relações de hegemonia - que, como tais, são políticas e, portanto, contingentes - mas por determinações externas ao campo do político, ou seja, pela posição dos sujeitos na estrutura social econômica. Isso fixa $a$ priori as identidades coletivas como um fato imanente e necessário da sociedade moderna cujo conteúdo está situado fora - nas leis imanentes do desenvolvimento capitalista - do campo das lutas políticas. Além disso, a preeminência da classe sobre todas as demais formas de identidade (determinação em última instância) reduz os conflitos sociais a determinações econômicas, e é por isso economicista. A centralidade de classe, pautada numa premissa economicista do social, deve ser, portanto, abandonada em favor de uma concepção aberta e discursiva da construção das identidades coletivas, uma vez que é o "discurso hegemônico, ao invés do contexto socioeconômico, que constrói a identidade do sujeito" (GOLDSTEIN, 2005, p.56); ou, em outras palavras, é a cultura e a sociedade civil ao invés da economia e da situação de classe. Essa impugnação da centralidade de classe permite a Laclau e Mouffe reafirmar a dimensão do político e do antagonismo como fundamentos ontológicos da vida social. ${ }^{4}$

\footnotetext{
${ }^{4}$ Segundo Burity (2008, p.35), "a pretensão de Laclau [e de Mouffe, acrescentaríamos] é [...] construir [...] precisamente, uma concepção da política como ontologia do social". E nas palavras de Mouffe (2003, p.14): "A tese central do livro [Hegemonia e Estratégia Socialista] é que a objetividade social é constituída através de atos de poder. Isso implica que qualquer objetividade social é definitivamente política".
} 


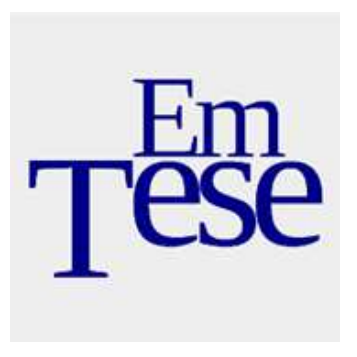

Junto ao antagonismo, o conceito de hegemonia constitui a noção chave para tratar a questão "do político". O fato de considerar "o político" como a possibilidade presente do antagonismo requer aceitar a ausência de um fundamento último e reconhecer a dimensão de indecidibilidade que domina toda ordem. Em outras palavras, requer admitir a natureza hegemônica de todos os tipos de ordem sociais e o fato de que toda sociedade é o produto de uma série de práticas que intentam estabelecer ordem em um contexto de contingência (MOUFFE, 2011, p.24).

Neste sentido, tudo é político para Laclau e Mouffe, uma vez que o antagonismo constitui o próprio fundamento ontológico da vida social (LACLAU e MOUFFE, 2001, p.xiv). Ou seja, nenhuma estrutura social está determinada fora do campo da agência, o que quer dizer que a sociedade é um arranjo instável e contingente - e, em certo sentido, impossível porquanto nunca pode se completar cabalmente - entre relações de poder antagônicas que estruturam a ordem (ou conferem sentido ao social) em torno de determinado discurso hegemônico. ${ }^{5}$

A noção de contingência - e, mais especificamente, de hegemonia como uma articulação contingente -, antitética à ideia do social como estrutura determinada por leis imanentes, é fulcral, e seu corolário mais significativo é a afirmação da "política como atividade autônoma", ao privilegiar "o momento político na estruturação da sociedade" (LACLAU e MOUFF, 2001, p.xii). Eis porque, partindo de um acerto de

\footnotetext{
${ }^{5}$ Não iremos entrar na análise da teoria do discurso, o quadro teórico-metodológico no qual se inscreve a teoria política de Mouffe. Importa notar aqui, sumariamente, que para ela o acesso à realidade é sempre mediado por um sistema de significados ao qual se dá o nome de discurso. Ou seja, a realidade não existe fora de um sistema de significados produzido socialmente. Em termos políticos, um discurso hegemônico é um elemento-momento dentro de uma formação discursiva mais ampla, cuja capacidade de encadear outros elementos (outros discursos diferentes) numa cadeia de equivalência confere-lhe uma posição hegemônica sobre o processo de significação do social. Nas palavras de Burity (2008, p.44), "uma formação discursiva é um conjunto de discursos articulados hegemonicamente por uma particularidade [...]. [...] aquele discurso que, naquele momento, é capaz de significar os fenômenos/interlocutores a que se dirige, de modo a oferecer-se como uma superfície de inscrição de diferentes demandas, em resposta a um desafio, uma crise ou uma ameaça percebida". Em suma: "É a essa capacidade de representar, enquanto posição particular, algo maior, mais abrangente, que Laclau dá o nome de hegemonia" (idem). Note-se que essa representação é sempre feita em relação a um exterior constitutivo, ou seja, ao mesmo tempo em que ela cria uma identidade ("nós"), ela necessariamente também cria um "eles" com o qual mantêm potencialmente uma relação antagônica. As implicações políticas desta dinâmica antagônica na formação discursiva das identidades - especialmente no caso das sociedades contemporâneas, onde elas são particularmente instáveis e cambiáveis - deverão ficar mais claras no decorrer desta exposição. Sobre a teoria do discurso em Laclau, ver Mendonça e Rodrigues (2008).
}

Em Tese, Florianópolis, v. 12, n. 1, jan./jul., 2015. ISSN: 1806-5023 


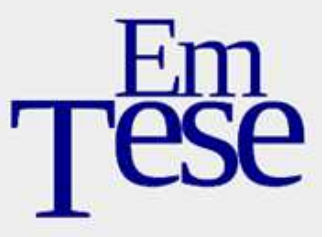

contas com o marxismo, Laclau e Mouffe têm como objetivo último reafirmar a autonomia da prática política e propor um novo modelo democrático, capaz, como veremos, de "transformar o antagonismo [inerente a toda formação social] em agonismo [próprio da democracia e, mais especificamente, de uma democracia agonística]" (MOUFFE, 2011, p.27; grifo do autor). Este é o objetivo que atravessa toda a obra de ambos os autores, mas será Mouffe quem o levará mais adiante no âmbito de uma discussão política normativa na tentativa de assentar as bases para fundar esse novo projeto de democracia radical e plural - ou ainda: "pluralismo agonista". Para ela, somente este novo projeto está em condições de transformar o antagonismo em agonismo, a luta entre inimigos numa luta entre adversários, e, assim, preservar e aprofundar o "projeto não realizado da modernidade", isto é, o "advento da revolução democrática" (MOUFFE, 1999, p.29-30).

\section{Antagonismo e impossibilidade do consenso: poder e hegemonia na constituição das identidades políticas}

Como já foi apontado, o objetivo de revalorizar o campo do político é um motivo constante nos escritos de Mouffe, perpassando toda a sua obra. Essa revalorização tem, ao menos, uma dupla dimensão: teórica e política. A teórica diz respeito ao papel do político na constituição da vida social (seu papel ontológico), e a prática à construção de uma nova ordenação político-social que aprofunde as instituições e práticas da democracia liberal em direção a uma democracia radical e plural.

Essa nova ordenação não está necessariamente lastreada na substituição - os marxistas diriam: superação - da sociedade capitalista por uma socialista através de uma revolução violenta levada a cabo pela classe trabalhadora. Já vimos que Mouffe rejeita a centralidade da classe na constituição de uma nova hegemonia como sujeito privilegiado por uma perspectiva universal em função de sua posição em algum campo

Em Tese, Florianópolis, v. 12, n. 1, jan./jul., 2015. ISSN: 1806-5023 


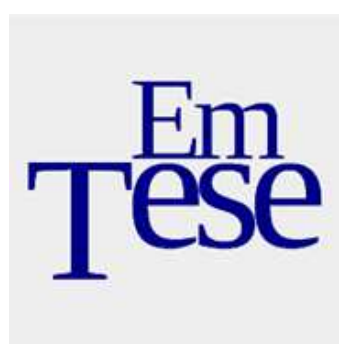

definido externamente ao político (no caso do proletariado, sua posição nas relações de produção). ${ }^{6}$ Ademais, a existência de uma sociedade democrática pressupõe, justamente, que nenhum sujeito monopolize para si a função de representar o todo. Por outro lado, à luz da experiência fracassada do comunismo soviético, que degringolou na perversão do stalinismo, Mouffe é cética quanto às possibilidades e pessimista quanto às consequências do "imaginário jacobinista" presente neste tipo de estratégia política. Com efeito, ela não acredita que o totalitarismo soviético tenha resultado apenas das condições sociais e econômicas vigentes na Rússia, mas também das premissas teóricas dadas no cerne do próprio marxismo ortodoxo.

Assim, Mouffe não se coloca contra o Estado democrático liberal, como se ele fosse apenas um engodo instrumentalizado pela classe dominante. Para falar em seus termos, ela não faz da democracia liberal um inimigo, a destruir ou ser por ela destruída numa irredutível luta de vida ou morte, mas antes um adversário com o qual se trava uma disputa agonística pela hegemonia. Na verdade, para Mouffe, a radicalização da democracia apenas pode se dar no quadro dos valores liberais que historicamente a fundamentaram, ou seja, a igualdade e a liberdade. A aceitação desses valores enquanto premissas que fundam o campo discursivo da democracia - é o único consenso legítimo numa sociedade democrática, sendo todo o resto matéria de disputa, inclusive a interpretação dada a esses valores e o modo de operacionalizá-los na prática, porque o que caracteriza a democracia é justamente a institucionalização - ou "domesticação", dirá Mouffe - do dissenso. ${ }^{7}$ Ou seja, o dissenso, o conflito, a disputa 6 "nenhum ator social pode atribuir a si mesmo a representação da totalidade e assim alegar ter o
'domínio' deste fundamento", o que implica dizer que "não pode haver emancipação total, mas apenas
parcial", e nenhuma sociedade pode realizar "o sonho de uma perfeita harmonia e transparência"
(MOUFFE, 2003, p.13-4). Como se sabe, essas suposições estão no cerne mesmo do pensamento
marxista.
7 Isto é, o único consenso que não está aberto à luta agonística: "todo consenso existe como um resultado
temporário de uma hegemonia provisória, como uma estabilização de poder que sempre vincula alguma
forma de exclusão [...]. [...] uma sociedade democrática dá oportunidade para a expressão de interesses e
valores conflitantes. A democracia pluralista demanda um certo consenso, mas tal consenso diz respeito
apenas aos seus princípios ético-políticos constitutivos" (MOUFFE, 2003, p.17). E ainda: "a confrontação
sobre as diferentes significações que se há de atribuir aos princípios democráticos e às instituições e

Em Tese, Florianópolis, v. 12, n. 1, jan./jul., 2015. ISSN: 1806-5023 


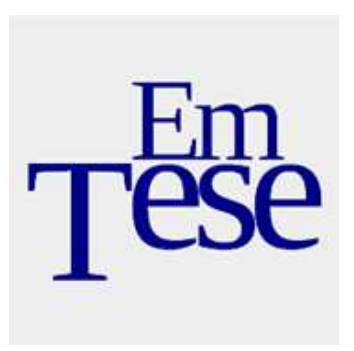

pela hegemonia ainda existem, na medida em que são, por definição, características inerradicáveis da vida social. Esse é o nível "do político", que não pode e - jamais deve ser obnubilado, sob pena de consequências negativas para a política democrática (como veremos). No entanto, a prática democrática exige que a disputa pela hegemonia se dê segundo regras formais, válidas para todos e em comum acordadas, que permitam que diferentes projetos de sociedade enfrentem-se no campo "da política" sem destruírem-se uns aos outros, isto é, sem destruírem a própria prática democrática ao erigirem-se em uma posição totalitária. ${ }^{8}$

Vejamos, então, como Mouffe (20103, p.15) define seu conceito de "o político":

Por 'político' refiro-me à dimensão do antagonismo que é inerente a todas as sociedades humanas, antagonismo que pode assumir formas muito diferentes e emergir em relações sociais diversas. 'Política', por outro lado, refere-se ao conjunto de práticas, discursos e instituições que procuram estabelecer uma certa ordem e organizar a coexistência humana em condições que são sempre potencialmente conflituosas, porque afetadas pela dimensão do 'político'.

A dimensão do antagonismo é vital para compreender tanto o modo de ser "do político", quanto os atuais desafios a ser enfrentados pelos partidários da democracia no terreno "da política". Para Mouffe, que propõe essa distinção entre o nível "do político" e o "da política" a fim de se pensar a democracia, é exatamente a diferença entre ambos, e a inerradicabilidade do poder, do dissenso e da hegemonia, bem como a formação das identidades nós/eles, que falham em compreender os pensadores liberais contemporâneos, sejam eles elitistas (incluída aí sua vertente pluralista), ou sejam deliberacionistas - que, em certo sentido, também podem ser considerados liberais.

A domesticação do dissenso é o que Mouffe chama de luta agonista, em oposição à luta antagonista. A primeira é própria de uma formação social específica, a

práticas nas quais se concretizam é o que constitui o eixo central do combate político entre adversários" (MOUFFE, 1999, p.19).

${ }^{8}$ Aqui ficam claras as razões pelas quais Mouffe rejeita o paradigma marxista clássico: primeiro porque ele concebe a identidade de classe como sendo determinada exteriormente e por uma lógica não-política (portanto, pré-determinada e fixa); segundo porque não abre espaço para o dissenso ao empreender a luta de classes pela ótica amigo/inimigo. Daí seu duplo potencial totalitário: essencialista e universalista.

Em Tese, Florianópolis, v. 12, n. 1, jan./jul., 2015. ISSN: 1806-5023 


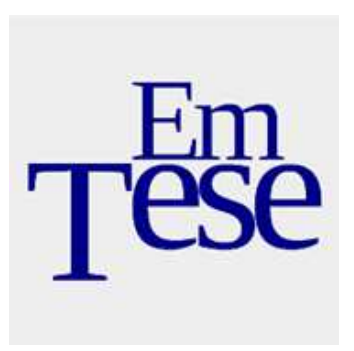

democracia; a segunda é intrínseca a qualquer formação social. Enquanto esta é caracterizada e enformada potencialmente por uma ótica "amigo/inimigo", aquela, ao contrário, vê na disputa política uma lógica “adversarial”. Ou seja:

a natureza da democracia moderna [...] supõe o reconhecimento da dimensão antagônica do político, razão pela qual só é possível protegê-la e consolidá-la se se admite com lucidez que $a$ política consiste sempre em "domesticar" a hostilidade e em tratar de neutralizar o antagonismo potencial que acompanha toda construção de identidades coletivas (MOUFFE, 1999, p.14).

Portanto, numa sociedade democrática ainda existem identidades sendo construídas em oposição a outras identidades - como não poderia deixar de ser, já que um exterior constitutivo é condição de possibilidade para que qualquer identidade venha a ser; isto é, a construção de um "nós" implica a existência de um "eles" -, mas os canais pelos quais se realiza o conflito potencial entre elas são agonistas e não antagonistas. ${ }^{9}$ Noutras palavras, na política democrática vigora a lógica adversarial. Ao contrário de inimigos, para os quais a aceitação mútua do direito à existência é impossível, adversários se batem em razão de suas distintas ideias, mas nunca questionam o direito recíproco de defendê-las. Isso significa que poder e hegemonia continuam existindo, mas as possibilidades de transformação das posições dos sujeitos dentro dessas relações são mediadas pelas regras democráticas. Tenhamos em mente esse último ponto.

Até aqui, aparentemente parece não haver muita diferença entre Mouffe e o adversário que ela constrói - o "eles" da democracia radical - e denomina "democratas liberais" grosso modo. É certo que ela recusa a tendência desses em conceber as

\footnotetext{
${ }^{9}$ O conceito de "exterior constitutivo" é de suma importância porque permite a Mouffe afirmar a primazia do momento político: “A ideia de um 'exterior constitutivo' ocupa um lugar decisivo em meu argumento, pois, ao indicar que a condição de existência de toda identidade é a afirmação de uma diferença, a determinação de um 'outro' que lhe servirá de 'exterior', permite compreender a permanência do antagonismo e suas condições de emergência. Com efeito, no domínio das identificações políticas [...], sempre existe a possibilidade de que esta relação nós/eles se transforme em uma relação amigo/inimigo, quer dizer, que se converta em base de um antagonismo. Isto se produz quando se começa a perceber o outro, o que aqui se considerava segundo o modo simples da diferença, como negação da nossa identidade e como questionamento da nossa existência. A partir desse momento, sejam quais forem as relações nós/eles, trate-se de ordem religiosa, étnica, econômica ou qualquer outra, converte-se em político no sentido schmittiano de relação amigo/inimigo.” (MOUFFE, 1999, p.15-6).
} 


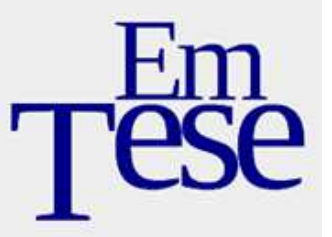

preferências políticas como se fossem formadas individualisticamente fora do espaço público - e que seriam, por conta disso, indignas de ser problematizadas pela ciência política. Quando ela diz, por exemplo, que "A prática política em uma sociedade democrática não consiste em defender os direitos de identidades pré-constituídas, mas consiste antes em constituir estas mesmas identidades em um terreno precário e sempre vulnerável." (MOUFFE, 2001, p.20), essa afirmação lembra os argumentos mais recentes das teorias normativas da representação política, que não a concebem como uma relação puramente ou de mandato ou de independência entre representantes e representados, entendidos como um agregado de preferências pré-constituídas, e afirmam que a relação de representação cria a comunidade e as identidades políticas (URBINATI, 2006). Nem são as preferências políticas de caráter privado nem individual. Ademais, tampouco são resultantes de cálculos estritamente racionais movidos por determinados interesses. Assim, a concepção de democracia de Mouffe não se confunde com o processo de agregação de preferências por meio do voto. Mas se a sua definição se restringisse a mecanismos de resolução de conflitos por meios pacíficos, ainda que não consensuais, a democracia radical se aproximaria perigosamente de uma perspectiva meramente procedimentalista, típica de um pluralismo elitista como é o de Schumpeter.

O que a diferencia definitivamente dos liberais - e, neste ponto, claramente também dos deliberacionistas - é o reconhecimento do papel do poder e da hegemonia na construção das identidades, bem como de que eles não podem (nem devem) ser simplesmente erradicados da prática política. O desafio de uma democracia radical é, precisamente, incorporar as relações de poder e dominação tornando-as visíveis. Embora os deliberacionistas vão além da democracia liberal como agregação de preferências políticas ao afirmarem a necessidade de revalorizar o debate público através da constituição de vários espaços públicos, eles falham em perceber que tais espaços não podem nunca ser neutros face às relações de poder e dominação que atravessam e estruturam toda a sociedade, como se pudessem ser barradas da porta para 


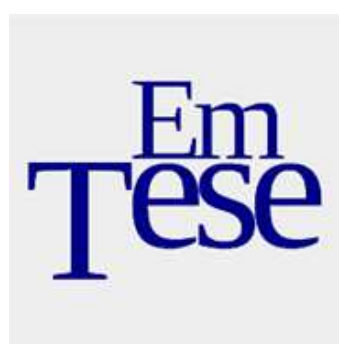

fora por meio da ação comunicativa racional (MIGUEL, 2014). E aqui entra o exato ponto da crítica de Mouffe: ela ataca o paradigma racionalista que está no cerne dessas concepções teóricas. Tanto para os pluralistas, quanto para os deliberacionistas, o poder e a hegemonia (quando os admitem) podem ser neutralizados pela razão, tornando desimportante a questão de como eles produzem as identidades coletivas, na medida em que se pode passá-las por alto mediante o efeito neutralizador e equalizador da razão. A implicação mais importante dessa concepção é que, através da argumentação racional, o consenso pode ser alcançado no campo político que - porquanto racional -, é objetivo e inteligível a qualquer sujeito, independentemente de sua posição na estrutura social.

Esse é, portanto, o fundamento epistemológico do consenso ao qual Mouffe se opõe tão ferreamente: o racionalismo - e ele põe de manifesto a dimensão "pós" do seu pensamento. ${ }^{10}$ "Concebida desta maneira [racionalista], a democracia pluralista se converte em um ideal que se autorrefuta" (MOUFFE, 1999, p.20). Ora, os móveis do campo político são, em última instância, valores, e diferentes valores são irredutíveis entre si. Ainda que admitíssemos que as diferenças de poder e recursos entre os sujeitos sociais pudessem ser barradas fora do espaço público, como supõe os deliberacionistas, a "verdade" de cada um deles não pode ser provada ou refutada pela lógica racional. ${ }^{11}$ Uma terceira consequência do racionalismo é que, além de ignorar as relações de poder e dominação constitutivas da sociedade ou que valores não são fatos, ele também exclui, por princípio, o papel do sentimento na prática política. Mouffe condena veementemente essa falha porque ela impede de reconhecer e mobilizar as paixões inevitavelmente presentes na prática política - a partir de um ponto de vista democrático. Por fim, o racionalismo é necessariamente universalista e individualista, e

\footnotetext{
10 "Hoje em dia é de bom tom, entre os supostos defensores do humanismo, rechaçar a contribuição de autores como Foucault, Derrida ou Lacan [...]. Acusam-nos de que, com sua crítica ao universalismo e ao racionalismo, minam as bases do projeto democrático. Na realidade, é exatamente o contrário. Pois os que põem em perigo a democracia são precisamente os racionalistas" (MOUFF, 1999, p.19).

${ }^{11}$ Isso não nos deve levar a concluir pela via do relativismo, contudo. "Afirmar que é impossível oferecer um fundamento racional último para um sistema de valores, qualquer que seja, não implica considerar iguais todos os pontos de vista. [...] Sempre é possível distinguir entre o justo e o injusto, o legítimo e o ilegítimo, mas com a condição de permanecer no interior de uma tradição dada, com ajuda dos padrões que essa tradição proporciona" (MOUFFE, 1999, p.34-5).
} 


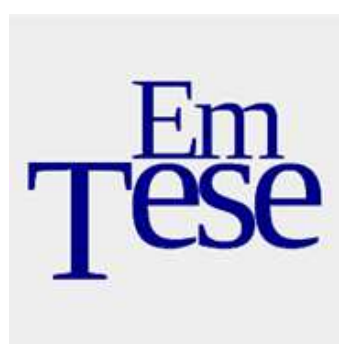

isso vai de encontro com o processo de constituição das identidades e da hegemonia, necessariamente contingentes e parciais. Daí também porque o consenso seria, para os racionalistas, possível: não apenas porque concebem a verdade em termos objetivos, alcançável pela deliberação racional, mas porque, posto que todos os indivíduos são potencialmente racionais, não há fundamento para nenhuma forma de exclusão. Para Mouffe (1999, p.12), entretanto, como deve ter ficado claro a este ponto, é impossível "constituir uma forma de objetividade social que não se funde em uma exclusão originária". Nas palavras de uma comentadora:

\begin{abstract}
o antagonismo constitui os limites de toda objetividade, a experiência do limite do social e sua impossibilidade de se constituir plenamente, uma vez que nunca consegue instituir a sociedade. A importância do antagonismo se deve ao fato de que ele fecha toda possibilidade de uma reconciliação final e de um nós plenamente inclusivo; a ideia de uma esfera pública sem exclusões, dominada pela argumentação racional, constitui uma impossibilidade conceitual. $\mathrm{O}$ conflito e a divisão são necessários mesmo à formação de uma política democrática e plural.

Nesse sentido, o projeto democrático deve reconhecer que não há possibilidade de uma resolução final e que toda forma de consenso é resultante de uma articulação hegemônica (ALVES, 2010, p.91).
\end{abstract}

Nesse sentido, embora Mouffe não use a expressão "exclusão justa”, parece-nos que a questão principal que a sua teoria política levanta não é como buscar a inclusão total através do consenso, e sim encontrar uma forma de exclusão que seja justa, isto é, que substitua as antigas formas de exclusão ao retraçar as fronteiras hegemônicas da sociedade. Essa é a finalidade e o grande desafio de uma democracia radical e plural, fundada numa prática política agonista e adversarial. Isso a teoria política dominante não pode fazer, de resto porque nem sequer se coloca tal problema.

Numa fórmula aparentemente paradoxal, Mouffe (2003, p.19) sintetiza da seguinte maneira a sua tese - que pela força explanatória vale a pena transcrever o longo parágrafo integralmente:

Tal privilégio ao consenso é, na minha visão, prejudicial à democracia porque tende a silenciar vozes dissidentes, e é por isso que acredito que uma abordagem que revele a impossibilidade de estabelecer um consenso sem

Em Tese, Florianópolis, v. 12, n. 1, jan./jul., 2015. ISSN: 1806-5023 


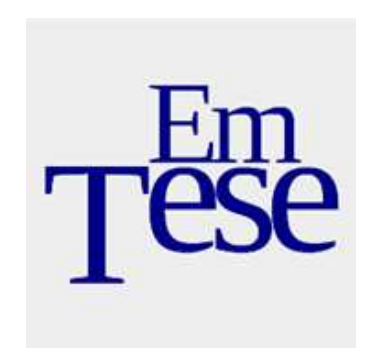

exclusão é de fundamental importância para a política democrática. Ao nos alertar contra a ilusão de que uma democracia plena poderia ser instaurada, ela nos força a manter viva a contestação democrática. Uma abordagem democrática "agonística" reconhece a natureza real das suas fronteiras e as formas de exclusão que elas englobam, ao invés de tentar disfarçá-las sob o véu da racionalidade e da moralidade. Ao estar consciente do fato de que a diferença é a condição da possibilidade de constituir a unidade e a totalidade, ao mesmo tempo em que ele fornece seus limites essenciais, tal abordagem agonística poderia contribuir para subverter a tentação sempre presente nas sociedades democráticas de naturalizar suas fronteiras e essencializar suas identidades. Ela seria pois muito mais receptiva que o modelo de democracia deliberativa à multiplicidade de vozes que uma sociedade pluralista encerra $\mathrm{e}$ à complexidade da estrutura de poder que esta rede de diferenças implica. Graças ao reconhecimento de que as identidades abrangem uma multiplicidade de elementos, tal abordagem está numa posição melhor para enfrentar uma identidade que acomoda outras, admite a porosidade das suas fronteiras e se abre em direção ao exterior que a torna possível. Aceitar que apenas o hibridismo nos cria como identidades separadas pode contribuir para dissolver o potencial da violência que existe em cada construção de identidades coletivas e criar as condições para um verdadeiro "pluralismo agonístico". Tal pluralismo está ancorado no reconhecimento da multiplicidade de cada um e das posições contraditórias a que esta multiplicidade subjaz. Sua aceitação do outro não consiste meramente em tolerar as diferenças, mas em celebrá-las positivamente porque admite que, sem alteridade e o outro, nenhuma identidade poderia se afirmar. Este é um pluralismo que valoriza a diversidade e o dissenso e não tenta estabelecer uma esfera pública a partir da sua eliminação, uma vez que reconhece neles a real condição da possibilidade de uma vida democrática a ser conquistada (MOUFFE, 2003, p.19).

Assim, revalorizar a dimensão "do político" é afirmar o antagonismo como "fundamental para a construção de lógicas, identidades e fronteiras políticas" (MENDONÇA, 2012, p. 205); é desconstruir o racionalismo individualizante e universalizante e "o essencialismo [que] conduz a uma visão da identidade que não concorda com uma concepção de democracia radical e plural” (MOUFFE, 1999, p.108109); é admitir a existência de relações de poder e hegemonia, isto é, de diferenças socialmente construídas, e sublimá-las - sem apagar (o que não passaria, na verdade, de uma tentativa frustrada de escamoteação) - mediante a criação de mecanismos pelos quais esses aspectos necessários das identidades coletivas e das relações entre elas 


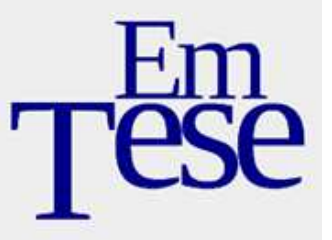

possam encontrar saídas democráticas. ${ }^{12}$ Mais importante ainda, de um ponto de vista radical-democrático, deve-se compreender que o pluralismo agonista não cai na relativização de todas essas diferenças, tal como o pluralismo tout court, mas aponta para o fato de que algumas delas são construídas como relações de dominação e, portanto, devem ser subvertidas (MOUFFE, 2000, p.20). Isso se faz, entretanto, no quadro de um modelo adversarial que possibilita a construção de um "nós" a partir de cadeias de equivalências articulando as demandas, contra um adversário comum, de diferentes grupos dominados e/ou subalternos: trabalhadores, mulheres, negros, homossexuais, imigrantes, etc.

Em suma, é nisto que consiste a crítica mouffeana ao que ela chama de "modelo de consenso", isto é, o paradigma racionalista que embasa correntes teóricas aparentemente tão diferentes quanto os pluralistas elitistas e os deliberacionistas: "a política democrática é por natureza necessariamente adversarial” (MOUFFE, 2011, p.128), e, "Longe de criar as condições para uma forma mais madura e consensual de democracia, o fato de proclamar o fim da política adversarial produz então o efeito exatamente oposto" (idem, p.82), isto é, mina tais condições. Isso é particularmente preocupante atualmente, diante dos inúmeros e urgentes desafios que estão a arrostar as sociedades contemporâneas e a democracia moderna e que são, ao mesmo tempo, causa e efeito da hegemonia desse modelo de consenso. Já vimos em que consistem, para Mouffe, alguns dos impeditivos teóricos para a apreensão correta desses desafios entre o pensamento político hegemônico. Agora vejamos a quais desafios ela se refere concretamente.

\section{Globalização, fim das ideologias, crise da esquerda e direita radical: desafios para um pluralismo agonista}

\footnotetext{
12 "Para que esta diversidade possa encontrar as condições para se expressar, deve entrar em cena a multiplicação das 'posições de sujeito' democráticas segundo dispositivos que permitem as diferentes posições enfrentarem-se no seio mesmo do que reconhecem como constitutivo de seu espaço político comum" (MOUFFE, 1999, p.22).
}

Em Tese, Florianópolis, v. 12, n. 1, jan./jul., 2015. ISSN: 1806-5023 


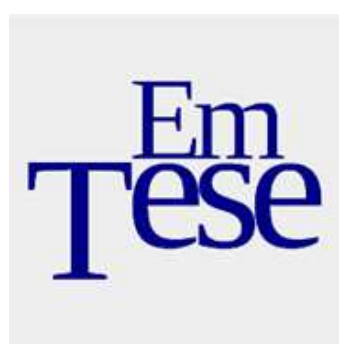

É mister deixar claro, de saída, que Mouffe não descreve e analisa sistematicamente os processos histórico-sociais que vamos discutir nesta seção em nenhum lugar específico. Ela basicamente usa-os, de passagem, em vários textos diferentes como contrapontos ilustrativos enquanto advoga a pertinência de seu próprio modelo pluralista agonístico, ou quando argumenta contra as teorias discordantes com ele. O que fizemos aqui, portanto, foi simplesmente recolher algumas dessas passagens a fim de estruturar coerentemente seu argumento, tecendo a narrativa dentro da qual Mouffe compreende os principais desafios empíricos contemporâneos a serem enfrentados na construção de uma nova hegemonia democrática por uma prática política radical.

Possivelmente, o principal dos grandes desafios identificados na contemporaneidade por Mouffe é a crise da esquerda. De fato, tema presente já em HSS, a avaliação de que o malogro do comunismo e o descrédito lançado sobre os socialistas e socialdemocratas com a hegemonização bem-sucedida do discurso neoliberal lançou a esquerda como um todo numa grave crise que constitui o ponto de partida e de chegada da reflexão da nossa autora. Mouffe se aproxima desse debate a partir de um ângulo especialmente abstrato, conceitual, apontando para as causas teóricas que respondem pela derrota do comunismo, às quais já fizemos menção aqui. Porém, além das limitações do marxismo, determinadas circunstâncias históricas e processos sociais confluíram para jogar a esquerda numa crise que, segundo Mouffe, ainda espera solução e da qual dependem as conquistas da modernidade, entre elas a própria democracia liberal.

Ocioso comentar o final desastroso da outrora auspiciosa experiência soviética, que, embora tenha conseguido industrializar e elevar a Rússia, um país agrário e semifeudal, ao status de superpotência econômica e militar, pagou o preço do totalitarismo sem poder realizar o sonho da igualdade socialista. Esse malogro, no entanto, foi ressignificado pela direita dentro de um discurso triunfalista que transformou, automaticamente, a derrota do comunismo em vitória do capitalismo - um

Em Tese, Florianópolis, v. 12, n. 1, jan./jul., 2015. ISSN: 1806-5023 


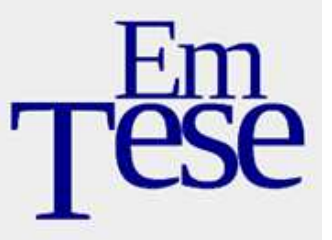

capitalismo com nome e sobrenome: neoliberal. Foi assim que intelectuais e arautos do "mundo livre" decretaram o fim de uma porção de coisas, segundo eles associadas com esse período histórico agora arcaico que o fim da Guerra Fria e o Consenso de Washington viriam a enterrar irrevogavelmente. Decretado o fim das ideologias e o fim da história, e coroado o capitalismo neoliberal vitorioso, a esquerda nada mais tinha a fazer neste mundo. Sua existência foi ab-rogada. E tanto na teoria quanto na prática política, diria Mouffe, foi exatamente isso o que aconteceu. A tese de que a distinção topográfica esquerda/direita perdeu sua função e seu valor neste novo mundo maravilhoso do consenso tornou-se senso comum. Teóricos apresentaram modelos que julgavam ir além dela. Políticos diziam-se nem de esquerda nem de direita, porque ser de direita ou de esquerda tornou-se quase um anátema. No jargão da política, surgiram termos novos e bisonhos como "centro radical" ou "república de centro". E Anthony Giddens propôs uma "terceira via" que foi encarnada no Novo Trabalhismo de Tony Blair, ajudando a descaracterizar de vez a esquerda socialdemocrata.

Com efeito, parte da culpa pela crise da esquerda pode ser creditada aos socialdemocratas, que se converteram em maior ou menor medida ao dogma neoliberal, o que jogou água no moinho dos patrocinadores do fim das ideologias. Ao borrar os contornos entre socialistas/socialdemocratas e liberais/conservadores, aparentemente até mesmo os mais aferrados à visão de campos políticos bem definidos davam razão à tese de que a distinção esquerda/direita não faz mais sentido no mundo de hoje. Surgiram novos atores, como os novos movimentos sociais, que se recusavam a deixarem-se enquadrar facilmente nessas tradicionais fronteiras ideológicas. Ao invés de interesses, reivindicavam valores, estilos de vida, o direito à alteridade. Ao invés da classe, mobilizavam-se em torno de questões locais e cotidianas, movimento que Giddens batizou de "política de vida". As próprias relações sociais pareciam se desfazer e fragmentar em um sem-número de identidades efêmeras, levando ao paroxismo o processo de individualização encetado pela modernidade. Nesse contexto, a lógica adversarial da política foi proscrita como arcaica e a política passou a ser visualizada,

Em Tese, Florianópolis, v. 12, n. 1, jan./jul., 2015. ISSN: 1806-5023 


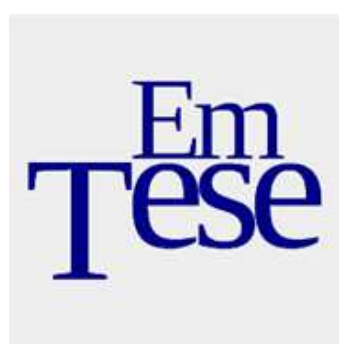

entrementes, não mais como uma disputa entre interesses particulares, mas como espaço de diálogo orientado para o consenso racional e o bem comum. Isso quando ela não se transformou em simples execução técnica de objetivos definidos fora do campo político, pelo processo de globalização que tudo arrasta e ao qual só resta se conformar.

Orientados por um método descritivo (e impressionista) típico de certa sociologia, Anthony Giddens - junto com Ulrich Beck - representa emblematicamente a sublimação teórica desse processo de formação do "modelo de consenso" na prática. Com efeito, Mouffe dedica um capítulo todo de On the Political para refutar sua proposta de "democracia dialógica" como "destradicionalização da política" no âmbito de uma "modernidade reflexiva". Como se trata de uma teorização complexa e sofisticada, não poderemos adentrar aqui nos detalhes da crítica mouffeana. Mais interessante para nós, contudo, é perceber suas implicações sobre as categorias de esquerda e direita, que Giddens julga obsoleta.

\begin{abstract}
Afirma [ele, Giddens] que, com a extinção do modelo socialista, e dado o fato de que já não há uma alternativa ao capitalismo, a principal linha divisória entre esquerda e direita desapareceu, e a maioria dos novos problemas que estão surgindo no contexto da sociedade pós-tradicional quer dizer, todas aquelas questões relativas à "política de vida" - não podem ser expressadas dentro do marco esquerda/direita (MOUFFE, 2011, p.51).
\end{abstract}

Essas ideias não seriam tão problemáticas se não expressassem uma tendência empírica presente na prática política contemporânea e se, num movimento de retroalimentação, não fossem vistas como a própria ratificação científica dessa tendência.

À luz do que foi exposto neste artigo, são óbvias as implicações desses processos históricos para o modelo teórico de Mouffe. A "perspectiva pós-política" (designação que Mouffe lhe dá por motivos que já devem ter ficado óbvios, mas sem a conotação positiva implícita na denominação, semelhante em certo sentido, "pósmarxismo" que ela adota), ou seja, o fetiche por um centro que se coloca ao mesmo tempo no meio e acima da divisão esquerda/direita, leva à recusa da lógica adversarial inerente à política democrática. Ainda pior, ignora a própria natureza "do político",

Em Tese, Florianópolis, v. 12, n. 1, jan./jul., 2015. ISSN: 1806-5023 


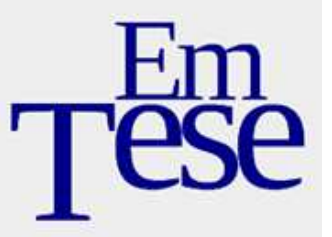

porque supõe que o antagonismo pode e deve ser erradicado "da política". Convergindo para o centro, não apenas a esquerda deixou de apresentar um projeto próprio, perdendo sua identidade, mas também a direita viu-se sem adversário, sem um "eles" que lhe representasse um exterior constitutivo em oposição ao qual apresentar um projeto identificável consigo mesma, relação que é condição de toda identidade, como vimos. Não surpreende que, mesmo negando a lógica adversarial, antagonistas acabem, não obstante, sendo procurados pelos defensores do consenso em outros lugares: se não mais no comunismo, agora no terrorismo, no tráfico internacional de drogas, no fundamentalismo religioso, etc.

A proliferação de conflitos étnicos, religiosos e identitários, aliás, foi menosprezada como se fossem resquícios anacrônicos legados pela etapa de "modernização simples", para usar a terminologia giddensiana, que todavia deveriam desaparecer à medida que a "segunda modernização" avançava. Essa perspectiva, segundo Mouffe, é incapaz de compreender a dinâmica de construção das identidades, rejeitadas por supostamente representarem particularidades desinteressadas pelo "bem comum" e indiferentes a argumentos racionais, pressupostos para a aquisição do consenso. "Muitas destas novas lutas renunciam de fato a toda pretensão de universalidade", como afirma Mouffe (1999, p.32). Mas os novos movimentos sociais, impulsionados pela fragmentação e transversalização das identidades, longe de impossibilitar a democracia, impulsionam-na, porque colocam em xeque o ideal racionalista e humanista unitário e põe a nu a função inerradicável do poder na constituição das relações sociais. O que caracteriza esses novos movimentos é a multiplicidade das posições de sujeito, o que implica a possibilidade sempre presente de antagonismo entre elas e de rearticulação constante das relações que estabelecem entre si. "A crítica feminista [por exemplo] desmascara o particularismo que se oculta detrás dos chamados ideais universais que, na realidade, sempre foram mecanismos de exclusão." (idem). 


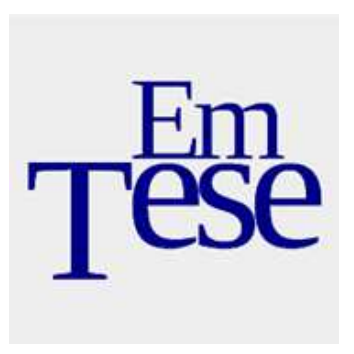

Ao invés da disputa hegemônica entre distintos projetos de sociedade, resta uma política estéril de busca por um consenso onde cada participante deve se despojar de sua identidade/particularidade a fim de se orientar para um bem comum que é e só pode ser, na verdade, a aceitação acrítica do status quo. Sem esquerda e direita não há alternativas reais entre as quais os sujeitos sociais possam optar e se posicionar. E a própria existência de alternativas reais e claramente identificáveis é condição de possibilidade de uma democracia pluralista. Nas palavras de Mouffe (2003, p.20):

\begin{abstract}
democracia pluralista [...] exige a criação de identidades coletivas em torno de posições claramente diferenciadas, assim como a possibilidade de escolha entre alternativas reais. Esta é precisamente a função da distinção esquerda/direita. [...]A obscuridade das fronteiras entre direita e esquerda que temos presenciado nas sociedades ocidentais, e que é frequentemente apresentada como um signo do progresso e da maturidade, é, em minha opinião, uma das mais claras manifestações da fraqueza da esfera pública política. É também a origem do crescente sucesso dos partidos de direita populistas. ${ }^{13}$
\end{abstract}

A assunção exitosa desses partidos ao centro da cena política contemporânea na Europa dá conta dos perigos que espreitam o modelo de consenso atrás de suas próprias deficiências, e constituem forte argumento em favor da tese de Mouffe. Por um lado, temos uma crise de representação fomentada pelas limitações de uma concepção democrática meramente agregativa de preferências individuais, cuja legitimidade deriva de um procedimentalismo cada vez mais posto em causa pela insatisfação crescente com o funcionamento das instituições representativas, especialmente partidos e parlamento. Por outro e decorrente da chamada crise de representação, vemos crescentes exigências de participação que cada vez menos podem ser ignoradas pelas elites nos processos de decisão pública - exigências que, entre intelectuais conservadores, suscitaram temores de crise de governabilidade. ${ }^{14} \mathrm{O}$ modelo de consenso, com sua recusa de toda forma de

13 "Neste crescente mundo 'unidimensional', no qual qualquer possibilidade de transformação das
relações de poder foram apagadas, não surpreende que partidos populistas de direita façam significantes
avanços em vários países. Em muitos casos eles são os únicos denunciando o 'consenso de centro' e
tentando ocupar o terreno de contestação abandonado pela esquerda." (MOUFFE, 2000, p.7).
14 "A tendência dominante de hoje consiste em conceber a democracia de tal modo que ela é quase
exclusivamente identificada com o Rechsstaat [Estado de direito] e a defesa dos direitos humanos,
deixando de lado o elemento da soberania popular, o qual é considerado obsoleto. Isto criou um "déficit

Em Tese, Florianópolis, v. 12, n. 1, jan./jul., 2015. ISSN: 1806-5023 


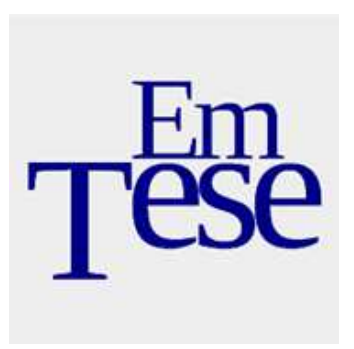

antagonismo, é incapaz de enfrentar esses problemas, cuja solução demanda uma tomada clara de posição orientada por um campo político dividido entre esquerda e direita. Como tudo o que ele oferece para combatê-los são esconjuros moralistas ou apego a uma crença iluminista de modernização e progresso, os cidadãos não conseguem identificar nenhuma alternativa real à ordem existente. Sem essa alternativa, o que lhes resta é a apatia, o cinismo, a alienação políticas, identificadas no decaimento das taxas de comparecimento eleitoral, de confiança nas instituições públicas e de filiação e identificação partidárias.

O sucesso da nova direita radical deve-se, precisamente, à sua capacidade de oferecer uma alternativa, construindo claramente uma identidade e um projeto específicos e definindo um inimigo (nota bene, inimigo e não adversário) contra o qual se colocar. Ou seja, deve-se ao fato de que, ao contrário dos partidários do consenso, ela não ignora a dimensão antagonista, hegemonista, identitária e passional intrínsecas à prática política e ao ordenamento da sociedade. Não ignora o papel do poder e das paixões, ao contrário, mobiliza-os. Não por acaso, enquanto os democratas liberais tornam as costas, confusos, à proliferação de novos conflitos étnicos, religiosos e identitários, a direita radical enxerga neles uma janela de oportunidades na qual pode capitalizar os descontentamentos, anseios e temores disseminados por vários setores da população. É por isso que, desde os anos 1980, a direita radical tem sido, em termos relativos, o ator mais bem-sucedido politicamente. Os riscos associados, entretanto, devem-se ao fato de que ela o faz a partir de uma perspectiva não democrática, definindo seu "eles" nos termos schmittianos de amigo/inimigo e não, tal como Mouffe defende que o façamos, democraticamente em termos de adversário. ${ }^{15}$

democrático" que, dado o papel central jogado pela ideia de soberania popular no imaginário democrático, pode ter perigosos efeitos negativos sobre a fidelidade às instituições democráticas." (MOUFFE, 2000, p.3-4).

15 “a desaparição de uma linha divisória clara entre os partidos políticos tradicionais [...] deixou, na realidade, um vazio que a extrema direita apressou-se a ocupar. Esse vazio é o que lhe permitiu articular novas identidades coletivas através de um discurso xenofóbico e recriar a fronteira política desaparecida mediante a definição de um novo inimigo [...]: os imigrantes” (MOUFFE, 1999, p.17-18).

Em Tese, Florianópolis, v. 12, n. 1, jan./jul., 2015. ISSN: 1806-5023 


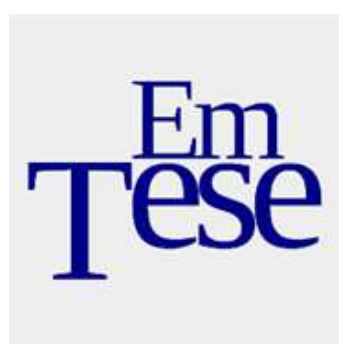

Para encerrar, pedimos licença para transcrever dois longos parágrafos de $O n$ the Political, que fecham formidavelmente os pontos da análise aqui empreendida e explicitam de forma sintética o pensamento político de Chantal Mouffe - ora, e quem melhor para fazê-lo senão a autora?

Afirmei que, como consequência do apagamento das fronteiras entre a esquerda e a direita e da ausência de um debate agonista entre partidos democráticos, isto é, de uma confrontação entre projetos políticos distintos, os votantes não têm a possibilidade de identificarem-se com uma gama diferenciada de identidades políticas democráticas. Isto criou um vazio que era provável que fosse preenchido por outras formas de identificação que poderiam tornar-se problemáticas para o funcionamento do sistema democrático. Sustentei que, apesar da anunciada desaparição das identidades coletivas e da vitória do individualismo, a dimensão coletiva não poderia ser eliminada da política. Se não eram oferecidas pelos partidos tradicionais, as identidades coletivas provavelmente seriam proporcionadas por outras formas. É claramente o que está ocorrendo com o discurso de direita, que substitui a debilitada oposição esquerda/direita por um novo tipo de nós/eles construído em torno a uma oposição entre "o povo" e "o establishment". Ao contrário de aqueles que creem que a política pode ser reduzida a motivações individuais, os novos populistas estão totalmente conscientes de que a política sempre consiste na criação de um "nós" versus um "eles", e que requer a criação de identidades coletivas. [...]

Se relacionamos isto com o argumento relativo à importância da dimensão afetiva na política e à necessidade de mobilizar as paixões através de canais democráticos, podemos compreender porque o modelo racionalista de política democrática, com sua ênfases no diálogo e na deliberação racional, é particularmente vulnerável quando é confrontado com uma política populista que oferece identificações coletivas com um alto conteúdo afetivo, como "o povo". Em um contexto no qual o discurso dominante proclama que não existe nenhuma alternativa à atual forma neoliberal de globalização e que deveríamos aceitar suas ordens, não resulta surpreendente que uma crescente quantidade de pessoas estejam escutando àqueles que proclamam que sim existem alternativas [...]. Quando a política democrática perdeu sua capacidade de mobilizar a gente em torno de projetos políticos distintos, e quando se limita a assegurar as condições necessárias para o funcionamento sem problemas do mercado, estão dadas as condições para o surgimento de demagogos políticos que articulem a frustração popular (MOUFFE, 2011, p.76-77).

\section{5. À guisa de conclusão: unir a esquerda, o grande desafio}

Em Tese, Florianópolis, v. 12, n. 1, jan./jul., 2015. ISSN: 1806-5023 


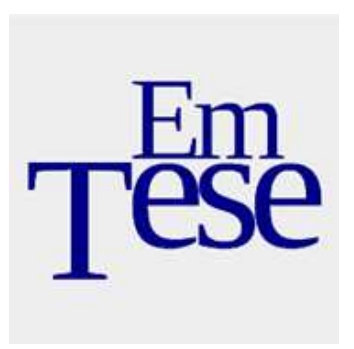

Como vimos nesta última seção, Mouffe identifica vários desafios urgentes esperando solução pela teoria e pela prática política contemporânea. A filósofa defende a tese de que - pelas razões expostas na segunda seção - a teoria política dominante (incluindo o deliberacionismo) é incapaz de fornecer respostas satisfatórias para esses problemas. Presos ao paradigma iluminista, eles não conseguem perceber que a crítica ao racionalismo, essencialismo e universalismo empreendida pela pós-modernidade é condição de possibilidade para preservar e aprofundar a democracia e não, como pensa Habermas, sua destruição. Portanto, uma resposta satisfatória àqueles problemas passa pela afirmação do antagonismo, do poder e da paixão como elementos constitutivos da prática política. Porque não ignora isso, advoga Mouffe, a proposta de democracia radical e plural - ou mais especificamente "pluralismo agonista" - está melhor capacitada para enfrentar tais desafios e levar adiante o projeto democrático fundado pela modernidade.

Esse leitmotiv é a grande preocupação de fundo que atravessa toda a obra de Mouffe, a problemática fundamental da autora. Sua grande questão é como substituir, por um pluralismo agonista, o "modelo de consenso" que hegemoniza a teoria e a prática política contemporânea, e que, incapaz de compreender a natureza antagonista do político, põe em risco a própria existência da democracia. Para tanto, deve-se reconhecer que o consenso é não apenas impossível como desastroso, já que vai contra a própria razão de ser da democracia, fazendo dela um ideal que se autorrefuta, na medida em que "o próprio momento da sua afirmação iria coincidir com sua desintegração" (MOUFFE, 2000, p.32). A democracia é, portanto, um paradoxo, e a tradição liberal é inábil para tratar com ele. Como o antagonismo não pode ser erradicado, na medida em que as identidades (multiplicadas pelo avanço da modernidade) sempre estão numa relação nós/eles indecidível que as limita e nunca deixa-as realizarem-se completamente, a tarefa do pluralismo agonista é transformar os antagonistas em adversários, os quais se, por um lado, compartilham um mesmo espaço simbólico, delineado pelos princípios ético-políticos e liberal-democráticos, por outro, discordam 


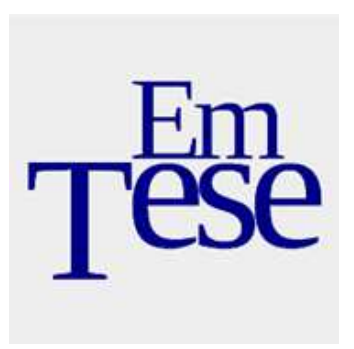

quanto ao modo de organizar esse espaço e lutam, conforme regras comuns, pela prerrogativa - a hegemonia - de fazê-lo.

Partindo deste modelo teórico, Mouffe propõe a constituição de uma cadeia de equivalências entre os grupos dominados capaz de articular as diferentes demandas desses diferentes sujeitos sociais, os quais, a despeito de suas diferenças, ligar-se-iam na e pela diferença contra um inimigo comum. Nesse sentido, gostaríamos de concluir, provisoriamente, chamando atenção para o fato de que, para além dos desafios teóricos e empíricos situados fora dessa cadeia de equivalências (passados aqui brevemente em revista), e que devem ser por ela superados, a própria articulação dessa cadeia, contudo, já é em si um desafio bastante considerável - e a nossa autora parece um tanto quanto otimista neste aspecto.

Quer nos parecer que a crítica de Mouffe é fundamentalmente pertinente. Ela toca em fraquezas-chaves do paradigma democrático dominante, da direita (liberais) ou da esquerda (socialdemocratas), tanto quanto da esquerda clássica revolucionária (comunistas), e apresenta uma saída plausível para seus impasses. No entanto, dado o nível altamente abstrato em que sua análise se situa, ela deixa em aberto como fazê-lo na prática. Ou melhor, fica claro que Mouffe aposta suas fichas na mobilização e organização dos inúmeros grupos sociais subalternos - além da classe trabalhadora - a partir da construção de uma cadeia de equivalências que permita identificar um adversário comum.

\begin{abstract}
A verdadeira aposta desta radical and plural democracy [sic] é a criação de uma cadeia de equivalências entre as diversas lutas pela igualdade e o estabelecimento de uma fronteira política capaz de conferir nova identidade à 'esquerda'. Uma esquerda que, mesmo sem questionar os princípios mesmos da legitimidade da democracia liberal, não obstante apontaria à transformação da relação de forças existente e à criação de uma nova hegemonia (MOUFFE, 1999, p.24).
\end{abstract}

Uma vez que ela parece abdicar da superação radical do capitalismo enquanto modo de produção - talvez por não visualizar uma alternativa viável, talvez porque toda alternativa tenha, até o momento, falhado -, esse adversário só pode ser o discurso hegemônico que atualmente organiza esse modo de produção, ou seja, o neoliberalismo

Em Tese, Florianópolis, v. 12, n. 1, jan./jul., 2015. ISSN: 1806-5023 


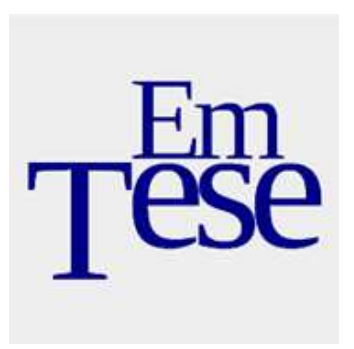

e sua versão eufemística identificada com a globalização, com suas funestas implicações sociais, políticas, econômicas, éticas e ambientais.

A fim de combater esse adversário, o problema maior está em como costurar uma cadeia de equivalências, conquanto contingente e precária, entre tantas identidades distintas e potencialmente antagônicas - "Pois não se trata de estabelecer uma mera aliança entre interesses dados, senão de modificar realmente a identidade mesma destas forças” (MOUFFE, 1999, p.39) -, com seus variegados interesses, valores, crenças, linguagens, práticas, etc., e como fazê-lo democraticamente, isto é, como construir uma nova hegemonia democrática que permita o dissenso e o conflito entre tantos sujeitos diferentes sem implodir a si mesma, ao mesmo tempo em que enfrenta um poderoso adversário (ou seria inimigo?) fora dela, o capitalismo neoliberal.

\begin{abstract}
Isto indica o reconhecimento comum, por parte dos diferentes grupos que lutam por uma extensão e radicalização da democracia, de que têm uma preocupação comum, e levará à articulação das demandas democráticas que levantam diferentes movimentos: as mulheres, os trabalhadores, os negros, os homossexuais, os ecologistas [...]. O objetivo é construir um "nós" como cidadãos democratas radicais, uma identidade coletiva articulada mediante o princípio de equivalência democrática (MOUFFE, 1999, p.121).
\end{abstract}

Esse "reconhecimento comum" é precisamente o acrônico problema da esquerda, e se, no pensamento marxista ortodoxo havia um princípio teórico que garantia a unidade desse campo de acordo com um suposto movimento da história (a centralidade de classe), na teoria mouffeana essas diversas posições de sujeito subalternos são potencialmente antagonistas, e não há nenhum princípio externo que garanta a construção dessa cadeia de equivalências progressista de esquerda. Como criar um "nós" amplo o suficiente para alterar as bases da hegemonia capitalista neoliberal quando ele está atravessado de tantos "eles"? Ou melhor: como manter tantos "eles" unidos por um "nós" em torno de um ideal democrático radical quando tantas questões práticas e concretas os fazem colidir e separar em tantas direções diferentes? O modelo de Mouffe pretende ser um espaço onde essas inúmeras identidades possam livremente convergir e divergir, mas também onde, acima disso, as divergências e convergências entre elas sejam a própria condição de possibilidade de existência deste espaço 


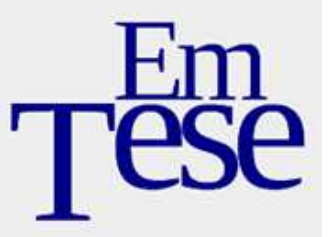

pluralista e agonista. Se, como acredita Bobbio (1995), o que sempre definiu a esquerda foi a igualdade como meta, esta tem sido, com efeito, a grande esfinge da esquerda desde a Revolução Francesa: unir uma pluralidade de vozes diferentes e desiguais contra um inimigo em comum. Um problema capital cuja dificuldade todo militante de esquerda conhece na prática e dois séculos de história dão conta. O trabalho de Mouffe, sem dúvida, é um passo necessário no sentido da decifração deste enigma e deve ser levado muito a sério por todos aqueles que acreditam na possibilidade de uma nova hegemonia democrática radical, plural e anticapitalista.

\section{Referências}

ALVES, Ana. O conceito de hegemonia: de Gramsci a Laclau e Mouffe. In: Lua Nova, São Paulo, v.80, 2010, p.71-96.

BOBBIO, Norberto. Direita e esquerda: razões e significados de uma distinção política. São Paulo: Editora da Unesp, 1995.

O conceito de sociedade civil. Rio de Janeiro: Edições Graal, 1982.

BURITY, Joanildo. Discurso, política e sujeito na teoria da hegemonia de Ernesto Laclau. In: MENDONçA, Dianel de; RODRIGES, Léo (orgs.). Pós-estruturalismo e teoria do discurso: em torno de Ernesto laclau. Porto Alegre: EDIPUCRS, 2008.

LACLAU, Ernesto. Identidad y hegemonía: el rol de la universalidade em la construción de lógicas políticas. In: BUTLER, Judith et al. Contingencia, hegemonía, universalidad: diálogos contemporáneos en la izquierda. Buenos Aires: Fondo de Cultura Económica, 2004.

LACLAU, Ernesto; MOUFFE, Chantal. Hegemony and socialist strategy: towards a radical democratic politics. London; New York: Verso, 2001.

GOLDSTEIN, Philip. Post-marxist theory: an introduction. New York: State Universy of New York Press, 2005.

MENDONÇA, Daniel de. Antagonismo como identificação política. In: Revista Brasileira de Ciências Sociais, Brasília, n.9, setembro-dezembro de 2012, p.205-228.

Em Tese, Florianópolis, v. 12, n. 1, jan./jul., 2015. ISSN: 1806-5023 


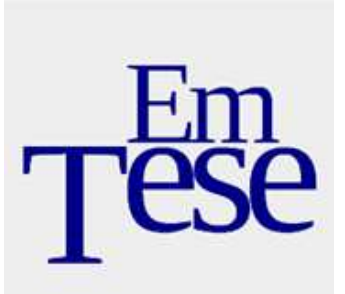

MENDONçA, Dianel de; RODRIGES, Léo (orgs.). Pós-estruturalismo e teoria do discurso: em torno de Ernesto laclau. Porto Alegre: EDIPUCRS, 2008.

MIGUEL, Luis. Democracia e representação: territórios em disputa. São Paulo: Editora UNESP, 2014.

MOUFFE, Chantal. Democracia, cidadania e a questão do pluralismo. In: Política \& Sociedade, Florianópolis, v.2, n.3, 2003, p.11-26.

. El retorno de lo político: comunidad, cidadanía, pluralismo, democracia radical. Barcelona: Ediciones Paidós Ibérica, 1999.

. En torno a lo político. Buenos Aires: Fondo de Cultura Econõmica, 2011.

. The democratic paradox. London: New York: Verso, 2000.

Globalização e cidadania democrática. In: Revista da Faculdade de Direito da UFPR, Curitiba, v.36, 2001, p.17-25.

THERBORN, Goran. From marxism to post-marxism?. London; New York: Verso, 2008 .

TORMEY, Simon; TOWNSHEND. Key thinkers from critical theory to post-marxism. London: Sage Publications, 2006.

URBINATI, Nadia. Representative democracy: principles e genealogy. Chicago: The University of Chicago Press, 2006.

Em Tese, Florianópolis, v. 12, n. 1, jan./jul., 2015. ISSN: 1806-5023 


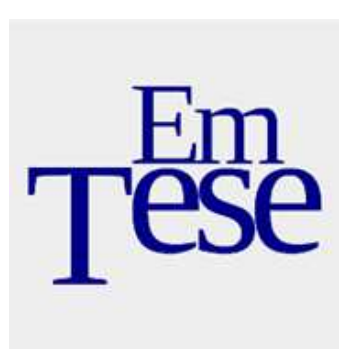

\section{Contra o consenso: o "político" em Chantal Mouffe e os desafios na construção de uma nova hegemonia democrática radical}

Resumo: O presente artigo se debruça sobre alguns dos problemas teóricos e empíricos levantados por Mouffe na constituição do que ela chama de nova hegemonia democrática radical e plural, uma preocupação que é o grande leitmotiv que atravessa sua obra como um todo, desde a publicação em 1985, com Ernesto Laclau, de Hegemony and Socialist Strategy. A resposta que ela dá passa, como veremos, pela reafirmação da dimensão "do político", isto é, do antagonismo contra o paradigma liberal-democrata hegemônico que supõe a possibilidade (e a desejabilidade) do consenso, e que ela denomina genericamente de "modelo de consenso". Além da conclusão e de uma breve introdução acerca das implicações teóricas das teses de Laclau e Mouffe para a tradição marxista da qual ambos se afastam, o artigo subdividese em outras duas seções. A primeira analisa o significado do político em Mouffe e suas relações com o pluralismo agonista advogado por ela, explicitando seus pontos de tensão com o modelo de consenso. Este é o momento dos problemas teóricos. Num segundo momento, a seção seguinte discute algumas implicações desses problemas em relação aos desafios empíricos que enfrenta a prática política contemporânea a fim de avançar em direção a uma democracia radical e plural. $\mathrm{O}$ artigo conclui chamando atenção para o que julgamos ser o desafio fundamental do modelo pluralista agonista: lograr unir, numa cadeia de equivalências democrática, uma esquerda tradicionalmente fragmentada por vários sujeitos sociais potencialmente antagonistas.

Palavras-chaves: Chantal Mouffe. Teoria democrática normativa. Pluralismo Agonista. Pós-marxismo

\section{Against consensus: the "political" on Chantal Mouffe and challenges in a new construction hegemony democratic radical}

Abstract: This article focuses on some of the theoretical and empirical issues raised by Mouffe in the constitution of what she calls the new radical and plural democratic hegemony, a concern that is the great leitmotif that runs through her work as a whole since the publication in 1985, with Ernesto Laclau, of Hegemony and Socialist Strategy. The answer she gives passes, as we shall see, through the reaffirmation of "the political" dimension, that is, of the antagonism against the liberal-democratic hegemonic paradigm that assumes the possibility (and desirability) of consensus, and that she generally calls "consensus model". In addition to the conclusion and of a brief 


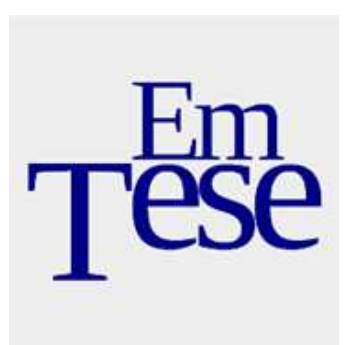

introduction about the theoretical implications of the Laclau and Mouffe's thesis for the Marxist tradition from with both depart, the article is divided into another two sections. The first analyzes the meaning of the political in Mouffe and their relationship with the agonistic pluralism advocate by her, making explicit their points of tension with the consensus model. This is the time of the theoretical problems. Secondly, the following section discusses some implications of these problems in relation to empirical challenges that the contemporary political practice faces in order to move toward a radical and plural democracy. The article concludes drawing attention to what we think be the fundamental challenge of pluralistic agonist model: get put together in a chain of democratic equivalences a left-wing traditionally fragmented by various potentially antagonistic social subjects.

Key-words: Chantal Mouffe. Normative democratic theory. Agonistic pluralism. Posmarxism.

Recebido em: 19 de março de 2015

Aceito para publicação em: 22 de maio de 2015

Em Tese, Florianópolis, v. 12, n. 1, jan./jul., 2015. ISSN: 1806-5023 